\title{
Community-Based Participatory Research (CBPR) needs assessment of parenting support programs for fathers
}

\author{
Shawna J. Lee ${ }^{\mathrm{a}, *}$, Gregory Hoffman ${ }^{\mathrm{a}}$, Donna Harris ${ }^{\mathrm{b}}$ \\ a University of Michigan School of Social Work, 1080 S University Ave, Ann Arbor, MI 48109, United States \\ ${ }^{b}$ Grace Learning Center of Detroit, 20021 W Chicago Rd, Detroit, MI 48228, United States
}

\section{A R T I C L E I N F O}

Article history:

Received 3 September 2015

Received in revised form 7 March 2016

Accepted 10 May 2016

Available online 11 May 2016

\section{Keywords:}

Urban

Men

Parent child relationship

Social welfare

Child welfare

Evaluation

\begin{abstract}
A B S T R A C T
This study reports the results of a Community-Based Participatory Research (CBPR) needs assessment of programs, services, and support systems for fathers in the City of Detroit, Michigan. The goal of this needs assessment was to assess the availability of parenting support services to men through multiple perspectives. To enact a CBPR approach, the research team collected qualitative data through interviews with service providers and community dialogues with fathers and consulted a community advisory board for further guidance on the research efforts. The research team engaged in member checking to improve the accuracy and credibility of study findings. Results indicated that both service providers and fathers agreed that very few parenting support services are available to fathers, particularly young African American fathers, and they also largely agreed in establishing priorities to address community fathers' parenting needs. Practice implications include the need for greater collaboration across service sectors and for greater outreach, possibly through technology, to young fathers.
\end{abstract}

(C) 2016 Elsevier Ltd. All rights reserved.

\section{Introduction}

Community-Based Participatory Research (CBPR) encourages partnerships between academic and community stakeholders to achieve "a balance between research and action" (Israel, Schulz, Parker, \& Becker, 1998) and to facilitate a co-learning process whereby community partners and researchers contribute equally. CBPR was appropriate for this needs assessment of fathering support systems for several reasons. First, community stakeholders voiced concern that while researchers have long looked at Detroit as a source of research participants, these efforts have not led to sustainable change for community members. Bilodeau et al. (2009) refer to this as "helicopter research," in which academics swoop into a community and temporarily engage a community organization to provide access to data or research subjects without enabling those organizations to directly benefit from the research findings. CBPR helps to address the lack of sustainable change that may result from helicopter research by involving community stakeholders as co-investigators who influence the research questions, data collection, data analysis, and data interpretation, and thus better positioning them to directly benefit from the knowledge generated by the research.

A second rationale for the CBPR approach was that community stakeholders (led by third author, Donna Harris) identified male engagement as a key priority. These stakeholders strongly believed that

\footnotetext{
* Corresponding author.

E-mail address: shawnal@umich.edu (S.J. Lee).
}

children cannot succeed without the positive support and engagement of both of their parents, and therefore sought ways to build fathers' capacity to serve as leaders within the family and the community. They noted concerns about non-residential father families (Hamer, 1997), as reflected in the number of single-parent-headed households in Detroit, which are nearly double the national average. In 2010, the rate of single-parent female-headed households with children under 18 years of age in Detroit was $59.3 \%$, compared to the national rate of 23.1\% (Data Driven Detroit, 2013; U.S. Census Bureau, 2010). The rate of single-parent male-headed households has also increased, comprising $10.8 \%$ of Detroit households compared to a national average of just 3.4\% (Data Driven Detroit, 2013; U.S. Census Bureau, 2010).

Most developmental theories acknowledge that there are multiple factors at the individual, family, and community levels that must be addressed in order to best promote child and family wellbeing, yet prior qualitative research suggests that men-and young African American men in particular-are underserved by parenting programs (Lee, Yelick, Brisebois, \& Banks, 2011; Stahlschmidt, Threlfall, Seay, Lewis, \& Kohl, 2013). Relatively few parenting interventions explicitly engage fathers or directly acknowledge fathers' parenting roles as a part of the family system. Lundahl and colleagues showed that when mothers and fathers were included in parent training programs, children seemed to experience greater reductions in problem behavior (Lundahl, Tollefson, \& Risser, 2008). Yet, in their meta-analysis, only a small number of studies of parent training programs had been tested with both mothers and fathers (Lundahl et al., 2008). Avellar and colleagues comprehensively cataloged a wide range of programs for low-income 
fathers, and showed that relatively few of these programs have been rigorously evaluated to show effectiveness (Avellar et al., 2011). More narrowly, in the field of child welfare, most evidence-based parent training programs were developed for mothers and evaluated with samples that largely or exclusively consist of mothers. For example, one of the most widely used child maltreatment prevention models, home visitation, explicitly focuses on the mother-child relationship (Olds, 2002).

The fact that men are underserved has previously been attributed to numerous factors, including fathers' seemingly low levels of interest in parenting support programs (Raikes, Summers, \& Roggman, 2005) and the programs' lack of cultural competency (Anderson, Kohler, \& Letiecq, 2002). Very few evidence-based parent training programs have been culturally adapted, and of those that have been culturally adapted, almost none have been rigorously evaluated (Baumann et al., 2015). Despite these gaps, promising research suggests that fathers can be effectively engaged in parenting support programs when the content is father-focused and culturally relevant-for example, a culturally embedded approach to promote African American fathers' parenting of adolescent sons (Caldwell, Rafferty, Reaischl, DeLoney, \& Brooks, 2010) and an empowerment approach to improve African American fathers' parenting attitudes and wellbeing (Fagan \& Stevenson, 2002).

A third rationale for the CBPR approach in a low-income urban community was the viewpoint of the authors and other stakeholders that the voice of African American men and fathers has largely absent in the research on fatherhood programs, with notable exceptions particularly in recent years (c.f., Anderson et al., 2002; Caldwell et al., 2010; Fagan \& Kaufman, 2015; Fagan \& Stevenson, 2002; Roy \& Dyson, 2010; Roy \& Kwon, 2007; Stahlschmidt et al., 2013). The partners in this project felt that identifying and prioritizing the needs of men with respect to their experiences as fathers and their interactions with service providers could potentially contribute to the development of locally relevant, culturally appropriate, and more acceptable services that recognize both the strengths and limitations of the community and population for whom these services are intended (Caldwell, Zimmerman, \& Isichei, 2001).

Other studies have examined barriers to father-child engagement such as maternal gatekeeping and co-parenting issues (Fagan, 2013; Fagan \& Kaufman, 2015; Fagan \& Lee, 2011; Roy \& Dyson, 2005; Waller, 2012), low employment (Roy, 2005), and the needs men returning to the community from the criminal justice system, also called returning citizens (Arditti, Smock, \& Parkman, 2005; Lewis, Garfinkel, \& Gao, 2007; Woldoff \& Washington, 2008). The main goals of this needs assessment project were to examine perceptions of the availability of parenting support services to fathers through the lens of (1) fathers' self-identified parenting needs and perceptions of existing programs, and (2) service providers' assessment of the availability and adequacy of existing services. To enact a CBPR approach, the research team collected qualitative data through interviews with service providers (SPs) and community dialogues with men. The research team established a community advisory board that was active in determining key research questions. Furthermore, the research team engaged in member checking, also known as "informant feedback" or "response validation," to improve the accuracy and credibility of study findings. Member checking is a process in which researchers present their results and interpretations of data to study participants and stakeholders for their additional feedback in order to ensure that the interpretation is consistent with respondents' intentions. Through this process, researchers are better able to fill gaps in understanding and clarify interpretations of study implications; plus, it supports the CBPR approach by providing a tool through which participants engage in the research process.

\section{Material and methods}

The study methodology and practice of data gathering was guided by Delgado's (1999) framework for collaborative community practice. The framework consists of a five interrelated stages for developing collaborations: (1) identification and assessment, (2) mapping nontraditional settings, (3) engagement and relationship building, (4) development of collaborative activities and projects, and (5) evaluation. This framework is consistent with the CBPR approach in that it identifies the formal systems in a community (i.e., health and human service agencies) while emphasizing the importance of "indigenous resources" such as hair salons and neighborhood elders (Delgado, 1999).

Fig. 1 illustrates the stages of research engagement, which the research team used in developing this project. Recognizing that community-engaged research is an interactive and nonlinear process, the activities necessarily overlap across domains. For example, the research team's efforts to map nontraditional settings significantly overlapped with the engagement and relationship building process.

\subsection{SP interviews}

The research team conducted a one-hour needs assessment interview with key informants in SP settings. SPs were identified in the identification and assessment phase of the project (see Fig. 1) and through snowball sampling techniques as input was received from SPs and advisory board members. The research team interviewed 26 individuals in 19 SP settings across the City of Detroit. SP respondents were predominantly male (69\%). Respondents reflected the race and ethnic distribution of Detroit, in that they were mostly African American (81\%), followed by White (12\%) and Hispanic ( $8 \%$ ). Every City of Detroit zip code except one was represented among the service areas of interviewees. The semi-structured interview assessed: (1) perceptions of fathers' needs in their community; (2) existing programming for fathers and/or efforts to engage fathers; (3) future programs that agencies would like to deliver to fathers; and (4) strengths of and barriers to engaging fathers in the service environment. Interviews were audio recorded and transcribed for data analysis. Following SP interviews, the research team debriefed to discuss broad theme. The University of Michigan Institutional Review Board approved all interview procedures. SPs received a $\$ 50$ honorarium for their participation.

\subsection{Fatherhood community dialogues}

The research team conducted community dialogues with 68 individuals that included 45 fathers and 23 SPs. The recruitment for community dialogues utilized a snowball recruitment methodology. The process for recruitment for the community dialogues was not representative of the Detroit population, however, based on feedback from our community advisory board as well as feedback from SPs who participated in SP interviews, community dialogue participants came from diverse settings. The research team conducted outreach to a range of community organizations such as Head Start, churches, and social service agencies. For example, one community dialogue was held at a Head Start location after the director of the program participated in a SP interview. One dialogue was held at a church. Another was held at a social service agency that had an active program to engage men and fathers. The first three community dialogues were each conducted in a different location with a unique sample of men. The final community dialogue consisted of primarily service providers and was a form of member checking by the research team, although all study participants were invited. See Table 1 for demographic characteristics of the fathers who participated in community dialogues. We did not collect demographic characteristics of the participants in the final community dialogue, most of whom were service providers.

Each dialogue had a slightly different topical focus, and the format for each event consisted of serving food and refreshments followed by a 1.5-h semi-structured group dialogue on the topics of fathers' parenting needs, access to parenting support services, and priorities for parenting support services. Dialogues were facilitated by either a member of the research team or a trained facilitator. Community dialogues with a larger number of participants, such as the first group, were 


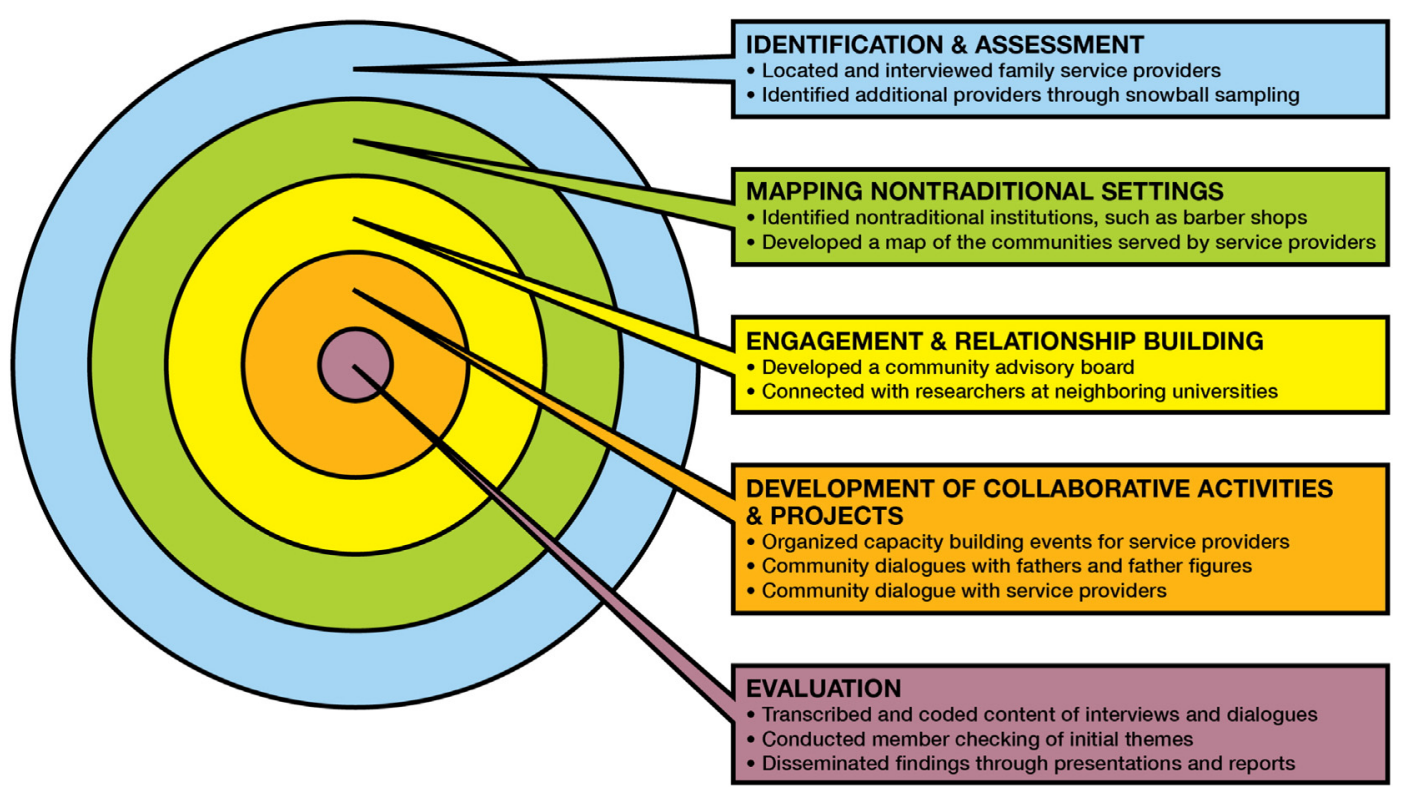

Fig. 1. Stages of community-engaged research.

broken into multiple smaller groups to ensure that each individual was able to contribute to the conversation. The dialogues were audio recorded and transcribed for data analysis. Following each dialogue, facilitators and the research team debriefed to discuss broad themes. The University of Michigan Institutional Review Board approved all interview procedures. Community dialogue participants received a $\$ 25$ honorarium to thank them for their participation.

Table 1

Community dialogue father participant demographic characteristics.

\begin{tabular}{|c|c|c|c|c|}
\hline Characteristic & $\begin{array}{l}\text { All fathers } \\
(\mathrm{n}=45)\end{array}$ & $\begin{array}{l}\text { Group 1 } \\
(\mathrm{n}=22)\end{array}$ & $\begin{array}{l}\text { Group 2 } \\
(\mathrm{n}=10)\end{array}$ & $\begin{array}{l}\text { Group 3 } \\
(\mathrm{n}=13)\end{array}$ \\
\hline Mean age years (SD) & $\begin{array}{l}40.95 \\
(10.22)\end{array}$ & $\begin{array}{l}34.38 \\
(6.51)\end{array}$ & $\begin{array}{l}42.30 \\
(4.14)\end{array}$ & $\begin{array}{l}50.54 \\
(10.69)\end{array}$ \\
\hline Average number of children (SD) & $\begin{array}{l}3.17 \\
(2.36)\end{array}$ & $\begin{array}{l}3.05 \\
(2.64)\end{array}$ & $\begin{array}{l}3.30 \\
(2.26)\end{array}$ & $\begin{array}{l}3.27 \\
(2.05)\end{array}$ \\
\hline $\begin{array}{l}\text { Avg. number of children in } \\
\text { home (SD) }\end{array}$ & $\begin{array}{l}1.45 \\
(1.37)\end{array}$ & $\begin{array}{l}1.36 \\
(1.26)\end{array}$ & $\begin{array}{l}1.80 \\
(1.81)\end{array}$ & $\begin{array}{l}1.30 \\
(1.16)\end{array}$ \\
\hline \multicolumn{5}{|l|}{ Marital status (\%) } \\
\hline Single, never married & 24.4 & 45.5 & 10.0 & 0.0 \\
\hline Living with partner, not married & 11.1 & 22.7 & 0.0 & 0.0 \\
\hline Married & 51.1 & 13.6 & 70.0 & 100.0 \\
\hline Separated & 6.7 & 4.5 & 20.0 & 0.0 \\
\hline Divorced & 4.4 & 9.1 & 0.0 & 0.0 \\
\hline Widowed & 2.2 & 4.5 & 0.0 & 0.0 \\
\hline \multicolumn{5}{|l|}{ Education level (\%) } \\
\hline Some high school & 6.8 & 9.5 & 10.0 & 0.0 \\
\hline High school diploma or GED & 25.0 & 38.1 & 20.0 & 7.7 \\
\hline Some college & 31.8 & 42.9 & 10.0 & 30.8 \\
\hline Associate's degree & 6.8 & 4.8 & 10.0 & 7.7 \\
\hline College degree or higher & 29.5 & 4.8 & 50.0 & 53.8 \\
\hline \multicolumn{5}{|l|}{ Residential father (\%) } \\
\hline Yes & 62.2 & 68.2 & 60.0 & 53.8 \\
\hline No & 37.8 & 31.8 & 40.0 & 46.2 \\
\hline \multicolumn{5}{|l|}{$\begin{array}{l}\text { Interaction level with children } \\
(\%)^{*}\end{array}$} \\
\hline $\begin{array}{l}\text { Much more involved than most } \\
\text { fathers in my community }\end{array}$ & 45.2 & 61.9 & 50.0 & 54.5 \\
\hline $\begin{array}{l}\text { Somewhat more involved than } \\
\text { most fathers in my community }\end{array}$ & 42.9 & 19.0 & 37.5 & 36.4 \\
\hline $\begin{array}{l}\text { Involved to the same extent as } \\
\text { most fathers in my community }\end{array}$ & 9.5 & 14.3 & 12.5 & 0.0 \\
\hline $\begin{array}{l}\text { Less involved than most fathers } \\
\text { in my community }\end{array}$ & 2.4 & 4.8 & 0.0 & 9.1 \\
\hline
\end{tabular}

\subsection{Community advisory board}

The research team used a purposive sampling approach to establish a community advisory board that met multiple times over the course of this one-year project. Key activities of the community advisory board were to determine the topics for community dialogues, identify key informants for SP interviews, and draft questions for SP interviews. During the member checking phase of the project, advisory board members provided input on the interpretation of key themes and ideas derived from content coding. Community advisory board participants received a $\$ 100$ honorarium to thank them for their participation.

\subsection{Data analysis plan}

The research team used semi-structured interviews for data collection; as such, data were naturally chunked into themes based on the interview protocol. For example, the first question posed to SPs was often about the needs of fathers in the community. Although we did not specifically utilize a grounded theory approach (Glaser \& Strauss, 1967; Corbin \& Strauss, 1990), our data analysis procedure and approach overlapped with basic components of grounded theory. Our analysis approach was inductive and grounded in the textual analysis of the dialogue and interview transcripts. Similar to grounded theory, we did not have a priori hypotheses at the start of the study; rather, we used coding and textual analysis to identify and categorize themes and identify relevant theoretical constructs based on interpretation of data.

Thus, the content coding focused on identifying different themes in respondents' responses to the questions as they elicited by the semistructured interview guide. The research team separated transcripts for SPs and dialogues, given that the content of the interviews and dialogues were different. A first step in data analysis involved initial debriefing on broad themes by all three study co-authors following interviews and community dialogues. Then the research team used a more formal procedure to review the transcripts and iteratively content coded them to identify program-specific themes, e.g., grouping responses based on the fatherhood-specific programming, family- or youth-serving programing, and non-specific programming such as medical clinic programming. The first two authors of the study manuscript conducted the initial content coding of the study transcripts.

The first two authors shared the initial content coding and data analysis with the manuscript third author. The research team discussed key 
themes. Although there were no major differences in coding and interpretation of the study transcripts, the study third author pointed out one additional theme to highlight, which was incorporated into the Results section. When all three authors arrived at consensus regarding the key themes and examples to illustrate those key themes, consistent with the CBPR approach the research team held several meetings to conduct member checking, a process to gather and utilize feedback from study participants and other stakeholders of interest. The research team used a PowerPoint presentation to share the coding process and resulting themes with members of our community advisory board, fathers who participated in the community dialogues, SPs who participated in interviews, and any other stakeholders who expressed interest in participating. The study second author conducted direct outreach via phone calls and emails to personally invite all study participants (e.g., community advisory board members, SP who completed interviews, and fathers who participated in community dialogues). The research team incorporated feedback from those individuals into the Results section as well as in the practice implications presented in the Discussion section of this manuscript. There were no major differences in interpretation of study themes during this process. Rather, the member checking process allowed the research team to delve deeper into themes, to answer questions about themes, and to gather more specific examples and anecdotes about the themes. The member checking process also allowed the research team to expand on the practice implications of this study, for example, regarding the use of technology to engage fathers and regarding the use of a collaborative practice model that utilizes an online learning community.

\section{Results}

\subsection{Results of SP interviews}

Presented first are the results of in-depth interviews with SPs, followed by the results of community dialogues. Recognizing the variety of contexts in which programs and services are conducted, the research team organized the SPs into three categories: (1) formal health and human services agencies ( $62 \%$ of respondents), (2) father-focused nonprofits ( $23 \%$ of respondents), and (3) "start-up" organizations and clubs ( $15 \%$ of respondents).

\subsubsection{Formal health and human service agencies}

SPs in this category were employed by established health and human service agencies. These organizations often employed a dedicated father outreach professional or conducted fatherhood outreach as part of general family supports. A number of these organizations were Head Start host sites, with fatherhood programs run through Head Start. Several of these SPs noted that fatherhood programs were previously a larger focus, at one time including a fatherhood manager and delegates from organizations in Detroit. Over time, budget cuts and a shift in focus resulted in less emphasis on fathers. One characteristic of this group was that although the SPs in this category had many years of experience in this field of social welfare and human services, they had limited knowledge of social media and other technology. One SP voiced this as a problem in his ability to connect with the younger generations of dads.

\subsubsection{Father-focused nonprofits}

Father-focused nonprofits were differentiated from the formal agency providers by their smaller size and sole focus on fatherhood-based services. The organizations were usually headed by leaders who acted as the face of the organization, and they often had a board of directors as well. Many times, these organizations funded their programming through a fellowship or small grant; other revenue streams included conducting workshops, selling branded merchandise, holding community fundraising events, and competing for foundation grants. Typically, the organizations maintained a web presence and used social media to publicize their events.

\subsubsection{Start-up organizations and clubs}

Another category of SPs were coined "start-ups," in part because they were small organizations that engaged in fatherhood or male youth program development outside of the government funded or nonprofit setting. Some of these SPs were partnered with religious institutions or operated from nontraditional sites such as barber shops. A characteristic of the start-ups was their heavy use of social media such as Facebook, Twitter, and YouTube to reach men. Most lacked a website or did not regularly maintain their website. Most also did not have a steady revenue stream or grant funding. Another common characteristic was their early developmental stage: these SPs were in the initial stages of strategic planning and only just beginning to document their programs and services and to develop a board of directors.

\subsubsection{Topic 1: what services do fathers need?}

The research team asked SPs about the biggest needs of the fathers they served, what was unique about the men with whom they worked, and if they there were adequate services for fathers in their community. Overwhelmingly, respondents said that services for fathers and men were inadequate. Several (2-3) individuals who indicated there were enough services for fathers added that, for the most part, men were unaware of these services.

3.1.4.1. Employment supports. The most consistent theme regarding fathers' needs was the need for employment support. SPs noted that employment issues were a significant barrier that kept many men from engaging with their children, due to both high levels of unemployment and underemployment (e.g., working multiple minimum wage jobs with little long-term stability). SPs discussed how unemployment and underemployment intersected with limited job skills training, insufficient education, a general lack of awareness about opportunities for additional education or training, and criminal records. One SP shared how lack of employment affects wellbeing, saying, "One of the main ingredients of manhood is dignity and pride, which employment often provides, and that is the main barrier that men face."

3.1.4.2. Navigating the child support system. Another theme was the need to help fathers navigate the child support system. SPs indicated that misconceptions about the child support system created long-term barriers to father engagement. For example, one misconception was the belief that the father cannot see his children if he has outstanding child support payments, with one SP saying, "A lot of the times the dads don't understand their rights; they don't know that she can't keep the kids away from you, even if you're not paying child support." Several formal agency SPs discussed programs to help men navigate the child support system, and some nonprofit and start-up SPs provided their own programs for fathers; yet, as discussed later, for the most part, fathers were not aware of these programs.

3.1.4.3. Needs of returning citizens. SPs working with returning citizens, or men returning to the community from the criminal justice system, noted the importance of helping men establish a trusting paternal relationship and re-engaging with their children. One SP with more than 20 years of experience working with returning citizens spoke of broken promises that hinder re-engagement, such as when incarcerated fathers make promises to their children while incarcerated but failure to deliver when they are released.

3.1.4.4. Positive fatherhood mentorship. The need for mentorship about what is means to be a positive, engaged father was another theme. The large majority of SPs attributed this need to the "fatherless home phenomenon"-that is, that the majority of the young men in Detroit today have been raised in single-parent female-led households and 
lacked a positive male role model in their childhood. In the view of SPs, men who were raised without an engaged father were more likely to grow up and themselves be absent or inconsistent in their fathering role. One SP discussed how he works with dads to understand how important it is that they just be present in their children's lives, especially at a young age, saying, "Dads need to know the real return on investment in those early years." Related to this, several SPs felt that many men narrowly defined fatherhood as being an economic provider. As some SPs put it, fathers think that providing material items fulfills their role as a father. Because many men struggle to find stable employment that would allow them to fulfill the economic provider role, inability to provide material goods becomes a barrier to father engagement in other domains.

3.1.4.5. Co-parenting relationship support. Related to this issue of fatherhood mentorship, another factor mentioned by nearly all SPs was the need for co-parenting support. As one SP put it, "Men have drama with the mothers and they don't know how to get around that in terms of getting information and being educated about how the legal system can help them reestablish those relationships." SPs mentioned how the mothers' expectations of the fathers were often unrealistic, particularly expectations regarding financial support.

\subsubsection{Topic 2: strategies for engaging fathers}

Following the SP interviews, the research team sought to obtain more feedback from SPs regarding their perceptions of best practices for engaging fathers. We conducted a community dialogue to ask SPs $(\mathrm{N}=23)$ in a small group format about their best practices, asking questions such as: (1) What has been successful in working with fathers; (2) What are some of the strategies that you have developed; and (3) What are some of the things that do not work with fathers/men in Detroit? We asked about the effectiveness of a range of specific strategies for engaging fathers, including collaboration with other services providers and advertising efforts through social media and Facebook, in order to understand how SPs connect with families and conduct outreach to engage individuals in their programs.

3.1.5.1. Meeting dads where they are. SPs described how rare it is for fathers to come in and ask for help, even when their need is significant. SPs noted that some fathers perceive an anti-dad stigma, which hinders their engagement with formal SPs. Therefore, a common engagement strategy was to meet the fathers where they are in the community, such as at schools where fathers drop off their children, at sporting events or parks, and at barbershops and restaurants. One SP discussed the lengths he goes to engage dads, saying, "Sometimes I'll drive past a past a bus stop and see ten guys at the bus stop and I'll stop and talk to them." Following from this theme was the idea of incentivizing involvement. SPs shared how they bundle parenting with other services, such as employment support resources, and then discuss fatherhood after they have developed greater rapport with the fathers. In other words, they work to develop "a mutual understanding that we've accomplished something. The dads need to feel like there is something they can wrap their arms around."

3.1.5.2. Showing empathy. The majority of the male SPs were fathers themselves, and many shared how important it was to empathize with and build rapport with fathers-for example, by sharing their own struggles as new fathers and stories of how they overcame or are still working to address fatherhood issues. SPs described how engaging with fathers more as peers than as service professionals helps them to develop trusting relationships. One SP described his approach as "planting seeds". He explained that as a new SP, he tried to get the fathers involved in the agency right away, which may have chased some away if they felt that he came on too strong. As he gained experience and greater empathy for each man's unique situation, he recognized that each small interaction gave him an opportunity to slowly cultivate a relationship and that, with patience, he could develop a much more trusting relationship with his clients.

3.1.5.3. Designing events that get dads excited. Another successful engagement strategy was hosting events that provide fathers opportunities to do something with their children, such as pancake breakfasts, sporting events, and picture days. One SP, in describing a Head Start T-ball game, emphasized the importance of developing programs that give both the father and child the opportunity to demonstrate the pride they have in their relationship. When fathers see, perhaps for the first time, the excitement and pride that their children have because their fathers are involved in the event, it can encourage the fathers to be more engaged with both their children and the agency.

3.1.5.4. Helping fathers reflect on their role. The SPs who spent time discussing the need for agencies to help fathers to reflect on their role as fathers also shared some of their own self-reflection methods, such as critical self-reflection on their interactions with their fathers during their own formative years or how the lack of their fathers' presence in their lives impacted them. Other SPs encouraged their participants to write letters to their own fathers, even if they never intended to send the letter, as a means of reflecting on their relationship with their own child. One SP shared how he begins workshops by asking how many of the participants have ever had a discussion about what it means to be a father. Some SPs mentioned that their curricula included sections on positive male leadership or fatherhood and the steps to being an effective father.

3.1.5.5. Identifying what doesn't work. A number of SPs mentioned that a "one size fits all" mentality is not effective with young, urban African American fathers; thus, programs have to be tailored to consider fathers' availability, work schedules, and other concerns such as whether they live with their child. Again, SPs noted the importance of being an active listener, sharing relevant experiences, and providing mentorship. SPs also noted challenges beyond engaging fathers, such as considerable competition among social service agencies for limited funding for programmatic efforts to engage fathers and agency instability; factors that are exacerbated by the poor economic conditions in Detroit.

\subsection{Results of community dialogues with fathers}

\subsubsection{Topic 1: engaging with children}

The research team asked fathers, "What are some of the ways that you have built a relationship with your child(ren)?" followed by prompts that encouraged men to share how they discovered their children's interests and what activities these men did with only their children. After discussing the positive activities and ways that men developed bonds with their children, the research team also asked that they share barriers that prevented them from engaging with their children: "What have been (or what are) the biggest barriers that you face in spending time with your child?"

3.2.1.1. Positive ways fathers engaged with their children. The fathers who took part in the dialogues were excited to share how they engage with their children. Some of the most common responses across the different dialogue groups involved the ideas of active communication and connecting through mutual interests. Several of the fathers discussed how important they felt it was to just sit down and talk to their children and actively listen to them in order to learn about their interests and opinions. As noted by one father:

"You sit there and you pay attention to them. And they'll presented to you, what they like to do. If you show interest into it, they gonna love you for that and they gonna want to do it more. Like I like to do it. I see you love me doing it. Let's do it together. Like my daughter is singing, 
she sings all the time. And if I act like I am interested, she turns it up (laughs)."

A few of the men who shared this idea talked about how they had learned the importance of communication the hard way: they did not communicate with their first child, and as a result had a very strained relationship with those children, who were now adults. This created a sense of urgency for these men to be more actively involved with their younger children.

In addition to actively communicating, the dads talked about getting involved with their children's interests, as well as sharing their own interests with their kids. One dad discussed how he will play with toys with his children or compete with them at video games. Sports seemed to be a very consistent bonding vehicle for these men and their children: watching sports on television, attending live sporting events, or playing organized sports. One father shared how he coached his children's sports teams, and how he was very aware of the pride his children took in that. He also spoke of his awareness that many of the other children on the teams don't have a consistent father figure in their life, so he was glad to have the opportunity to serve as a role model to those children as their coach. Another father spoke about taking walks around the neighborhood:

"I do the walks. I like doing the walks around the neighborhood, especially when they are younger because they ask so many questions. You know what I'm saying. It's the time for them really get information from you. You know "dad' what's that?" even if they know it they still ask for confirmation. I like the walks as well."

3.2.1.2. Barriers to engagement. When fathers were prompted to discuss barriers that they face in building a relationship with their children, a frequent concern was the lack of a positive relationship with their child's mother. Once that topic was mentioned, it was often difficult for the facilitators of the dialogues to redirect the conversations to other barriers. Fathers expressed ideas that were similar to those of SPs, especially the disconnect between their idea of fatherhood and mothers' expectations about their role. When the father did not live up to the expectations of the mother, it created friction and maternal gatekeeping. For example, one father participated in a community dialogue noted:

"I got two kids, my barrier is I don't see them that much. I only get them for the summer. I could try to get them for the holidays but baby mama be dropping them. I got to deal with her saying no and all that. You know."

Unemployment and underemployment often contributed to unmet expectations and further exacerbated the friction between the father and the mother. Several of the fathers discussed their own financial burdens, made worse by child support obligations. Employment itself also created a barrier to fathers building relationships with their children, as employed participants often found themselves with even less time to spend with their children. One father shared how his work schedule-midnight shifts, with his days off falling in the middle of the week-made it very difficult to see his kids, because by the time he got home, they were off to school, and then when they arrived home, he had to leave for work. Another father in a community dialogue noted that it was hard to "shift" roles from work to home, saying that, "As soon as I walk in the home, I get a parade, "daddy, daddy, daddy" and so they automatically want you to go into daddy mode and I just got off work mode. You know so that sometimes can be a barrier as well, ones job."

\subsubsection{Topic 2: interactions with SPs}

The research team asked fathers about how they interact with family service agencies, asking, "What programs or agencies in your community are you aware of that provide parenting supports?" The dialogue facilitators posed follow-up questions about the reasons that fathers don't utilize parenting support services, even if they are aware of such services in their communities.

3.2.2.1. Anti-father bias of human service agencies. Some, but not all, participants expressed feelings that SPs were oriented toward mothers, which created what they perceived as an "anti-dad" environment. Plus, in such an environment, they faced judgment by the mothers using the services. One father shared the story of going to a WIC office and receiving negative feedback, in the form of looks and comments, from the mothers who were in the waiting room. One father noted, "It's hard doing that because with the system there's lots of females when they looking at you, the first thing they say is where is mama? Like I didn't kidnap my daughter."

Additionally, some men avoided certain organizations because they felt judged by SPs, specifically mentioning the biases of governmental programs. One man who was a single father to his child expressed the opinion that "[DHS] and WIC are more of a hassle than a help because they send you through a whole bunch of process and send you on the runaround," and added his opinion that many men avoid these offices altogether because they face negative stereotypes of the SPs at these agencies.

3.2.2.2. Masculine identity. Fathers shared that masculine pride made it more challenging to reach out to SPs for assistance. Several fathers indicated that they initially felt shame or as though they were admitting defeat when they first utilized services that could be interpreted as charity-such as food or clothing banks-which suggests that the receipt of services was intertwined with the father's masculine identity as the provider or breadwinner.

Some fathers, however, described a sense of relief at accepting help. One dialogue participant, a single father of two young children, spoke about how he was always on the lookout for assistance programs and services in the surrounding communities, and that once he found them, he would not only use these resources, but would also spread the word about them to his peers.

“...It too me a long time to swallow my pride on a lot of stuff. There's a lot of churches out here that help you, even with clothes. My son was 4, his first two years, I bought stuff for him but I didn't really have to pay for nothing because I searched for churches that gave away clothes. They gave away food. They gave away diapers and I ain't gonna lie, that shit helped out a lot bro. I had to swallow my pride but low key it saved me a lot of money he had coats he had everything."

3.2.2.3. How SPs can support fathers. The research team asked fathers, "How can programs ... help you as a father?" The SP community dialogue participants were also asked to share their thoughts on what agencies can do to better support the fathers who use their services. One recurring suggestion involved the correction of "anti-dad" biases by the agencies. SPs that have a goal of integrating fathers into their program delivery need to create an agency environment that normalizes the presence of men. Beyond normalizing the environment, though, SPs may be able to better engage fathers by tailoring their programs specifically to the needs of fathers. One father shared an anecdote about a meaningful interaction he'd had with a SP who helped him to develop critical reflection skills by taking him through some exercises to reflect on his experiences growing up without a residential father. This father shared how developing these critical thinking skills extended beyond his parenting and also informed his decisions in his relationship with his spouse and in his professional career. 


\section{Discussion}

CBPR served as a model for this research project to engage stakeholders and enrich the substance of the qualitative data. The SP interviews and community dialogues presented a diverse range of viewpoints, but within the common context of a large urban area. Of note, one prior study also interviewed SPs and fathers. Stahlschmidt et al. (2013) conducted a study of SPs and fathers that compared the responses of SPs to those of fathers in focus groups, and identified a number of service provision themes similar to those found in the current study. Similar to Stahlschmidt et al. (2013), SPs in the current study strongly acknowledged the importance of engaging fathers. Yet, in the current study the research team noted that only a few of the formal SPs had a clear, defined strategy for engaging this population.

The needs of fathers as identified by the SPs were consistent with those that the fathers themselves identified in community dialogues, likely stemming from the shared geographic context (Detroit) and widespread acknowledgement of the challenges that disproportionately face African American men, and that also impact parenting. The member checking process, in which the research team consulted with a community advisory board and research participants regarding interpretation of data, confirmed the notion that viewpoints of SPs and fathers were largely consistent. Furthermore, the member checking process led to greater insight regarding the practice implications of the study results.

Study results underscored the need for increased collaboration among family service agencies and a particular need to develop organizational capacity to serve fathers, especially in many of the start-up organizations that are characterized by a great deal of passion for assisting fathers but limited training in program development and evaluation to reproduce positive results and make adjustments when necessary. As such, strategic service models, such as the model discussed in Berkel, Mauricio, Schoenfelder, and Sandler (2010), would be applicable to service providers in Detroit. This model encourages approaching service delivery as a collaborative process between service provider and consumer, in which the service provider is continually evaluating their program's impact and efficacy, and, when necessary, adapting aspects of the program to the needs of the service consumers (Berkel et al., 2010). Thus, the discussion focuses on aspects of the study results that specifically address capacity building, including: (1) the use of collaborative practice models; (2) the use of mentorship-based programmatic models to engage fathers; and (3) strategies to reach fathers that involve technology and social media.

\subsection{The use of collaborative practice models}

A growing trend is the concept of a learning community, also frequently referred to as a community of practice. This is an educational model that embraces learning as a social activity where peers are both teachers and learners, working collaboratively. Learning communities are characterized by community members interacting to mutually establish norms and values, hold each other accountable, and share community resources and best methods (Wenger, 2000). A learning community model is particularly applicable to fatherhood engagement because information is shared on a peer-to-peer level, rather than handed down by authority figures, thus contributing to the development of inclusive and trusting relationships (Fulton, 2012; Jessup-Anger, 2015).

One commonly observed problem in community settings is lack of resources. Many - nearly all - of the SPs in this study noted how limited resources hindered their ability to collaborate and provide services. Thus, in settings with few resources, the online learning community model and technology-based approaches may be a future way that social work practitioners can enact agency collaboration. The online learning community requires relatively few resources-mainly Internet access, social media, and free conference call services. Social media is at the crux of an online learning community's ability to promote the dissemination and exchange of information between experts, peers, and the community at large. Research points to the fact that social media and similar technology can be effective tools within a community for sharing information and ideas because of the way that collaborators interact through the technology; collaborators gain access to knowledge both through their observation of others' conversations and through direct digital connections to experts and peers on the topic(s) of interest. Additionally, there is a compounding effect: as information sharing becomes more frequent, the research demonstrates that participants become increasingly engaged and active in the sharing and more willing to seek out answers and initiate discussion, thus expanding the knowledge base (Leonardi \& Meyer, 2015). The ability to collaborate and share online in this way, with the engagement of any interested party in a given community-expert or not-supports the objective of a learning community, which is sharing information on a peer-to-peer level.

\subsection{Strategies to reach fathers that involve technology and social media}

One of the questions we asked SPs to comment on was about their efforts and best practices to engage fathers (see Section 3.1.5). The three types of SP categories (formal health and human services agencies, father-focused nonprofits, and "start-up" organizations and clubs) had differing strengths and weaknesses in their efforts to engage fathers. SPs in the formal health and human service category particularly demonstrated a wealth of experience working with fathers, but many of these SPs were of an older generation than the young fathers they sought to engage. It did not appear that these SPs were unwilling to adapt and integrate more modern approaches; rather, they seemed to have established routines that had been successful in the past but may be decreasing in relevance as technology becomes more integrated into the daily lives of younger generations. As one SP stated, "In the old days, we used flyers, which were a good way to connect ... but the problem is, we're still using these methods today." There was a nearly unanimous response that social media was an effective tool to engage fathers, but most of the formal SPs had not embraced technology as an outreach tool.

The start-up SPs had a more pronounced social media presence in lieu of a formal organizational website. However, these start-up SPs lacked sufficient funding and experience of working with fathers in a structured service delivery environment and maintained less emphasis on long-term planning or service evaluation; as a result, their programs and events were not consistently reproducible. The results seem to suggest that organizations would benefit from greater collaboration, especially in strategies for engagement such as social media. Formal SPs and nonprofits could help the start-ups plan and evaluate their services, and the start-ups could help the other two increase their social media presence and, consequently, help them to better engage a younger generation of fathers.

\subsection{The use of mentorship-based models to engage fathers}

One of the key themes to emerge from this study was fathers' strong desire for social support and mentorship around the issues they face as fathers. In every group, fathers discussed their wish to connect to other fathers in the community in order to share their experiences and learn from the experiences of other fathers. Many of the SP professionals shared their own stories in response to the interview questions about what inspired them to pursue their line of work: often they were inspired by the relationship, or lack of relationship, with their own fathers.

Through the SP interviews and dialogues with fathers, the notion of mentoring emerged as a crucial component of any fatherhood programs, with an emphasis on engaging young men before they become fathers. Mentoring enhances influences youth social-emotional development, which includes how a person connects to others and forms relationships (Rhodes, Spencer, Keller, Liang, \& Noam, 2006). Additionally, mentoring has a positive influence on cognitive development and 
identity development, by helping youth to think in a more positive and concrete manner about their future (Rhodes et al., 2006). There is comparatively little research on adult mentoring to inform father-to-father mentoring programs, but there is an abundance of research on the components of effective mentoring programs for adolescents that could be tailored to both youth mentoring and mentoring adult fathers. For example, Karcher, Kuperminc, Portwood, Sipe, and Taylor (2006) cite infrastructure and dosage as two essential foci in developing mentoring programs in their analysis of evidence-based mentoring programs. Infrastructure includes "screening, matching, training, and ongoing support of mentors," while dosage includes amount or frequency of mentor-mentee interactions, the intensity of the relationship, and the duration of the mentoring relationship (Karcher et al., 2006). Based on the findings of the present study, a direction for future research is to consider how evidence-based strategies from adolescent mentorship research could be modified or adapted to inform the development of fatherhood mentorship programs. A mentorship program approach, in which older more experienced men are matched with younger new fathers, may help young fathers (particularly those who did not have an engaged father) develop a sense of efficacy about their role as fathers and begin to develop a new personal narrative about how they hope to engage with their young child.

\subsection{Study limitations}

This qualitative needs assessment of services and support systems for fathers in Detroit is strengthened by the fact that the study was guided by a CBPR approach and was relatively novel in that it included the perspectives of both fathers and community services providers. Nonetheless, the study has a number of important limitations. First, the data analysis approach is largely descriptive. Furthermore, the results may not be generalizable. The metro Detroit area has a high unemployment rate (approximately 13\%) compared to 5\% nationally in 2016 (USBLS). Detroit is a majority African American city, with $82.7 \%$ of the City population identified as African American in the 2010 U.S. Census. Thus, the results of this study may be especially relevant to social workers and social services providers working in similar contexts.

\section{Conclusions}

This study adds to a growing body of literature that documents the needs of fathers-particularly African American fathers-in order to create a better understanding of how to provide parenting services and programs to this population. The research approach was strengthened by the use of CBPR, which emphasized the voices of community stakeholders in an effort to identify and prioritize the needs of the fathers with respect to their experiences as fathers and with regard to their interactions with SPs.

\section{Acknowledgements}

The authors would like to thank the fathers and service providers who participated in this study, as well as Grace Learning Center and Grace Church, in Detroit, Michigan. This study was funded by a Michigan Institute for Clinical \& Health Research (MICHR) Community University Research Partnership (CURES) Grant called Building Community Capacity to Implement Multi-Level Parenting Support for Fathers, awarded to the first and third authors of this manuscript.

\section{References}

Anderson, E. A., Kohler, J. K., \& Letiecq, B. L. (2002). Low-income fathers and "responsible fatherhood" programs: A qualitative investigation of participants' experiences. Family Relations, 51(2), 148-155. http://dx.doi.org/10.1111/j.1741-3729.2002.00148.x.

Arditti, J. A., Smock, S. A., \& Parkman, T. S. (2005). "It's been hard to be a father": A qualitative exploration of incarcerated fatherhood. Fathering, 3(3), 267-288.
Avellar, S. M., Dion, R., Clarkwest, A., Zaveri, H., Asheer, S., Borradaile, K., ... Zukiewicz, M. (2011). Catalog of research: Programs for low-income fathers (OPRE Report \#2011-20). U.S. Department of Health and Human Services, Administration of Children and Families, Office of Planning, Research, and Evaluation (Retrieved from:) http://www.acf. hhs.gov/programs/opre/resource/catalog-of-research-programs-for-low-incomefathers

Baumann, A. A., Powell, B. J., Kohl, P. L., Tabak, R. G., Penalba, V., Proctor, E. K., ... Cabassa, L. J. (2015). Cultural adaptation and implementation of evidence-based parent-training: A systematic review and critique of guiding evidence. Children \& Youth Services Review, 53, 113-120.

Berkel, C., Mauricio, A., Schoenfelder, E., \& Sandler, I. (2010). Putting the pieces together: An integrated model of program implementation. Prevention Science, 12(1), 23-33. http://dx.doi.org/10.1007/s11121-010-0186-1.

Bilodeau, R., Gilmore, J., Jones, L., Palmisano, G., Banks, T., Tinney, B., \& Lucas, G. I. (2009). Putting the "community" into community-based participatory research: A commentary. American Journal of Preventive Medicine, 37(6), S192-S194. http://dx.doi.org/10. 1016/j.amepre.2009.08.019.

Caldwell, C. H., Rafferty, J., Reaischl, T. M., DeLoney, E. H., \& Brooks, C. L. (2010). Enhancing parenting skills among nonresident African American fathers as a strategy for preventing youth risky behaviors. American Journal of Community Psychology, 45(12), 17-35. http://dx.doi.org/10.1007/s10464-009-9290-4.

Caldwell, C. H. Zimmerman, M. A., \& Isichei, F. P. A. (2001). Forging collaborative partnerships to enhance family health: An assessment of strengths and challenges in conducting community-based research. Journal of Public Health Management and Practice, 7(2), 1-9. http://dx.doi.org/10.1097/00124784-200107020-00003.

Data Driven Detroit (2013). State of the Detroit child: 2012 report. (Retrieved from) http://datadrivendetroit.org/portfolio/?text $=$ state + of + the + detroit + child (on July $13,2015)$

Delgado, M. (1999). Social work practice in nontraditional urban settings. New York, NY: Oxford University Press.

Fagan, J. (2013). Adolescent parents' partner conflict and parenting alliance, fathers' prenatal involvement, and fathers' engagement with infants. Journal of Family Issues, 35(11), 1415-1439. http://dx.doi.org/10.1177/0192513X13491411.

Fagan, J., \& Kaufman, R. (2015). Co-parenting relationships among low-income, unmarried parents: Perspectives of fathers in fatherhood programs. Family Court Review, 53(2), 304-316. http://dx.doi.org/10.1111/fcre.12152.

Fagan, J., \& Lee, Y. (2011). Do coparenting and social support have a greater effect on adolescent fathers than adult fathers? Family Relations, 60(3), 247-258. http://dx.doi. org/10.1111/j.1741-3729.2011.00651.x.

Fagan, J., \& Stevenson, H. C. (2002). An experimental study of an empowerment-based intervention for African American head start fathers. Family Relations, 51(3), 191-198. http://dx.doi.org/10.1111/j.1741-3729.2002.00191.x.

Fulton, W. (2012). Community learning: Broadening the base for collaborative action. National Civic Review, 101(3), 12-22. http://dx.doi.org/10.1002/ncr.21082.

Glaser, B. G., \& Strauss, A. (1967). The discovery of grounded theory: Strategies for qualitative research. Chicago, IL: Aldine Publishing Company.

Corbin, J., \& Strauss, A. (1990). Grounded theory research: Procedures, canons, and evaluative criteria. Qualitative Sociology, 13(1), 3-21.

Hamer, J. F. (1997). The fathers of "fatherless" black children. Families in Society, 78(6), 564-578. http://dx.doi.org/10.1606/1044-3894.3387.

Israel, B. A., Schulz, A. J., Parker, E. A., \& Becker, A. B. (1998). Review of community-based research: Assessing partnership approaches to improve public health. Annual Review of Public Health, 19(1), 173-202. http://dx.doi.org/10.1146/annurev.publhealth.19.1. 173.

Jessup-Anger, J. (2015). Theoretical foundations of learning communities. New Directions for Student Services, 147, 17-27. http://dx.doi.org/10.1002/ss.20114.

Karcher, M., Kuperminc, G., Portwood, S., Sipe, C., \& Taylor, A. (2006). Mentoring programs: A framework to inform program development, research, and evaluation. Journal of Community Psychology, 34(6), 709-725. http://dx.doi.org/10.1002/jcop. 20125.

Lee, S. J., Yelick, A., Brisebois, K., \& Banks, K. L. (2011). Low-income fathers' barriers to participation in parenting programs. Journal of Family Strengths, 11(1), 1-16 (Retrieved from) http://digitalcommons.library.tmc.edu/jfs/vol11/iss1/12/

Leonardi, P., \& Meyer, S. (2015). Social media as social lubricant: How ambient awareness eases knowledge transfer. American Behavioral Scientist, 59(1), 10-34. http://dx.doi. org/10.1177/0002764214540509.

Lewis, C. E., Garfinkel, I., \& Gao, Q. (2007). Incarceration and unwed fathers in fragile families. Journal of Sociology \& Social Welfare, 34(3), 77-94 (Retrieved from:) http:// scholarworks.wmich.edu/jssw/vol34/iss3/5

Lundahl, B., Tollefson, D., \& Risser, H. (2008). A meta-analysis of father involvement in parent training. Research on Social Work Practice, 18(2), 97-106. http://dx.doi.org/ $10.1177 / 1049731507309828$.

Olds, D. L. (2002). Prenatal and infancy home visiting by nurses: From randomized trials to community replication. Prevention Science, 3(3), 153-172.

Raikes, H. H., Summers, J. A., \& Roggman, L. A. (2005). Father involvement in early head start programs. Fathering, 3(1), 29-58. http://dx.doi.org/10.3149/fth.0301.29.

Rhodes, J., Spencer, R., Keller, T., Liang, B., \& Noam, G. (2006). A model for the influence of mentoring relationships on youth development. Journal of Community Psychology, 34(6), 691-707. http://dx.doi.org/10.1002/jcop.20124.

Roy, K. M., \& Dyson, O. L. (2005). Gatekeeping in context: Babymama drama and the involvement of incarcerated fathers. Fathering, 3(3), 289-310. http://dx.doi.org/10. 3149/fth.0303.289.

Roy, K. M., \& Dyson, O. (2010). Making daddies into fathers: Community-based fatherhood programs and the construction of masculinities for low-income African American men. American Journal of Community Psychology, 45(1-2), 139-154. http://dx.doi. org/10.1007/s10464-009-9282-4. 
Roy, K. M., \& Kwon, Y. I. (2007). Qualitative insights and methodological challenges: Next steps in research on low-income fathering. Applied Developmental Science, 11(4), 234-238. http://dx.doi.org/10.1080/10888690701762142.

Roy, K. M. (2005). Transitions on the margins of work and family life for low-income African-American fathers. Journal of Family and Economic Issues, 26(1), 77-100. http:// dx.doi.org/10.1007/s10834-004-1413-3.

Stahlschmidt, M. J., Threlfall, J., Seay, K. D., Lewis, E. M., \& Kohl, P. L. (2013). Recruiting fathers to parenting programs: Advice from dads and fatherhood program providers. Children and Youth Services Review, 35(10), 1734-1741. http://dx.doi.org/10.1016/j. childyouth.2013.07.004.

U.S. Bureau of Labor Statistics (2016, April). The Unemployment Situation - April 2016. Washington, D.C.: Bureau of Labor Statistics, U.S. Department of Labor. Available online at: http://www.bls.gov/news.release/pdf/empsit.pdf.
U.S. Census Bureau, Housing and Household Economic Statistics Division, Fertility \& Family Statistics Branch. (2010). Living arrangements of children under 18 years/1 and marital status of parents, by age, sex, race, and Hispanic origin/2 and selected characteristics of the child for all children: 2010. (Retrieved from) www.census.gov/population/www/socdemo/hh-fam/cps2010.html

Waller, M. R. (2012). Cooperation, conflict, or disengagement? Coparenting styles and father involvement in fragile families. Family Process, 51(3), 325-342. http://dx.doi.org/ 10.1111/j.1545-5300.2012.01403.x.

Wenger, E. (2000). Communities of practice and social learning systems. Organization, 7(2), 225-246. http://dx.doi.org/10.1177/135050840072002.

Woldoff, R. A., \& Washington, H. M. (2008). Arrested contact: The criminal justice system, race, and father engagement. The Prison Journal, 88(2), 179-206. http://dx.doi.org/10. 1177/0032885508319154. 